Alma Mater Studiorum - Università di Bologna DEPARTMENT OF ECONOMICS

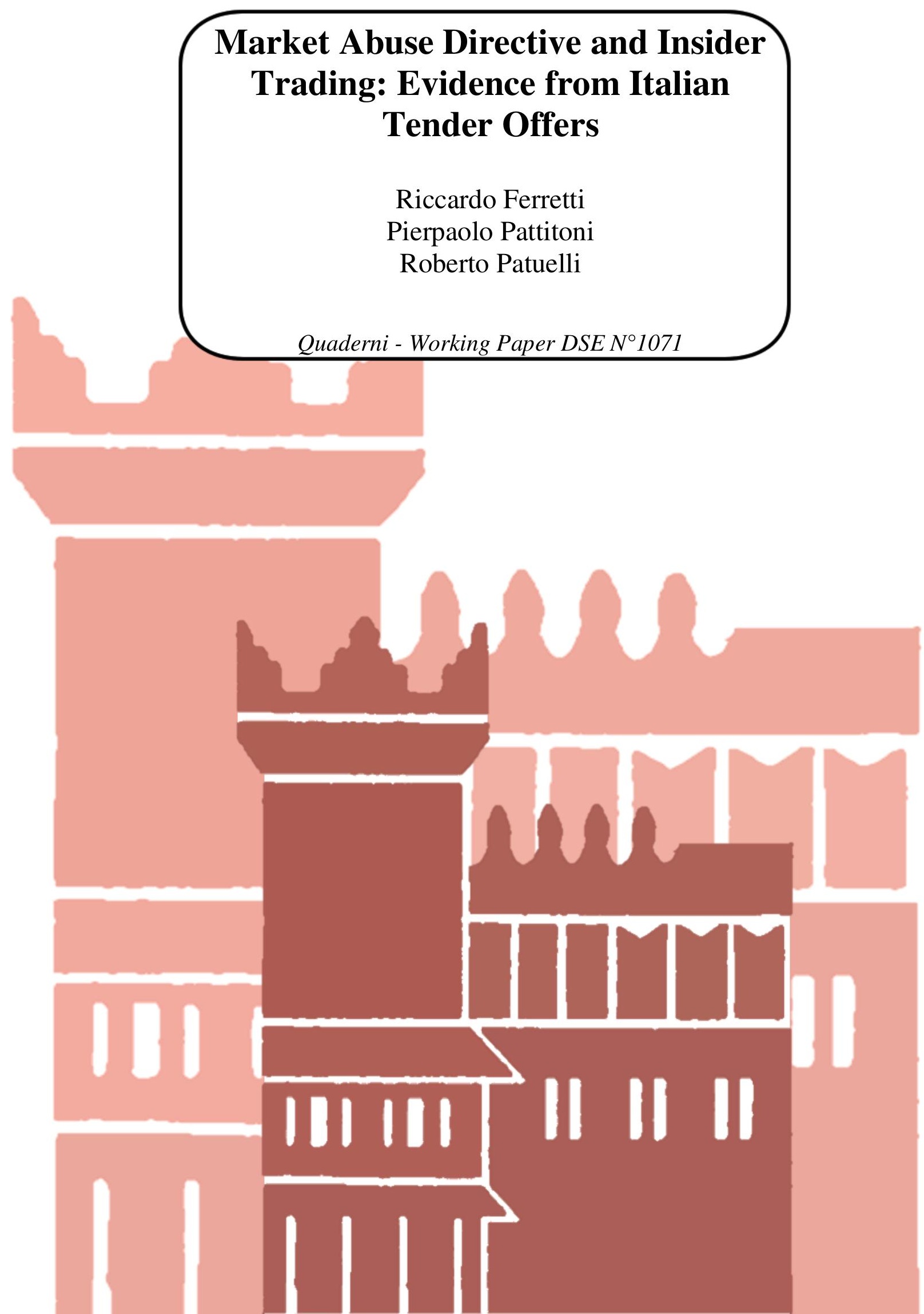




\title{
Market Abuse Directive and Insider Trading: Evidence from Italian Tender Offers
}

\author{
Riccardo Ferretti* \\ University of Modena and Reggio Emilia
}

Pierpaolo Pattitoni

University of Bologna

Roberto Patuelli

University of Bologna

This study analyzes the effectiveness of the Market Abuse Directive (MAD) in reducing possible profits from insider trading during voluntary tender offers with the purpose of delisting initiated by controlling shareholders. Exploiting the quasi-experimental setting provided by the introduction of the MAD, our event-study analysis on the Italian market suggests that the new regulation did not produce appreciable effects on the magnitude of abnormal returns and volumes noted before the announcement of a tender offer. Multivariate econometric analyses based on regression and matching methods confirm this result. However, poolability tests reveal that the MAD has changed the manner in which corporate characteristics influence the capacity of insiders to make profit. We interpret our results considering the choice problem of the optimal amount of insider trading, when comparing the marginal costs and benefits of the illegal activity.

Keywords. Market Abuse Directive - Tender offer · Delisting · Event study

JEL Classification. K2 · K4 · G34 · G14

* Department of Communication and Economics, and Cefin (Centro Studi Banca e Finanza), viale A. Allegri, 9, 42121 Reggio Emilia. Email: riccardo.ferretti@ unimore.it. Corresponding author.

A previous version of this paper circulated under the title "The effectiveness of insider trading regulations: The case of the Italian tender offers". We wish to thank Anna Salinas, who participated in the data collection process, and all participants to the Annual Meeting of the European Association of University Teachers in Banking and Finance held in Granada (Spain), 2-5 September 2015. 


\section{Introduction}

In many countries, primary and secondary regulation intended to prevent and punish the abuse of privileged information (so-called 'insider trading') have been in place for quite a long time (Linciano 2003). As Rose and Søpstad (2015: 248) note,

(t)he motivation for regulating insider trading is based upon an assumption that markets will function better and be more efficient if all participants are on an 'equal footing'.

In a related vein, European regulation (Directive 2014/57/EU) states that

(a)n integrated and efficient financial market and stronger investor confidence requires market integrity. The smooth functioning of securities markets and public confidence in markets are prerequisites for economic growth and wealth. Market abuse harms the integrity of financial markets and public confidence in securities, derivatives and benchmarks.

If insider trading (Madura et al. 2014) increases the conflict between minority shareholders (outsiders) and managers and/or controlling shareholders (insiders), an effective regulation should reduce agency costs and therefore increase firm value, even though the literature is not unanimous on the negative role of insider trading in the agency relationship (Beny 2008). ${ }^{1}$ Beny (2008) finds indeed that, in common law countries, stricter insider-trading regulation and enforcement do increase firm value. However, the same result is not found in civil law countries, where, Beny (2008: 292) notes, 'investor protections are relatively weaker'. Therefore, the effectiveness of insider trading regulation may depend on the institutional context (Beny, 2008).

Furthermore, the introduction of insider-trading regulation does not always produce the desired effects. ${ }^{2}$ For example, Bris (2005), examining a sample of 52 countries, documents that the introduction of insider-trading regulation makes, at times, insider trading even more 
profitable without appreciably decreasing its frequency. As Bris (2005: 309) notes, this puzzling result is at the heart of the 'fundamental dilemma' faced by regulators: 'by prohibiting insider trading, they make it more profitable'.

In the European Union, insider-trading regulation is contained in the Market Abuse Directive (Directive 2003/6/CE - MAD) (Engelen 2006; Forbes 2013). In 2011, the European Commission proposed a MAD reform to address its ineffective application in individual member states. Such reform came to fruition in 2014 with the transformation of the MAD into Regulation 596/2014 (MAR) and the introduction of the Directive 2014/57/EU (MAD2), intended to establish a framework for criminal prosecution. Both MAR and MAD2 will be effective on 3 July 2016.

Our study is motivated by the debate on the revision to the MAD, and by the conflicting results of insider-trading regulation documented in the scientific literature. In order to identify the critical aspects of the MAD and propose potential changes to improve its effectiveness, it is necessary to assess the effects of this Directive from the moment in which it came into effect. In our analysis, we specifically focus on the possibility of earning profits from insider trading during voluntary tender offers made with the purpose of delisting and initiated by controlling shareholders.

We chose this type of operation, which we describe in detail commenting the case study of Benetton in Appendix A, because, as noted by Keown and Pinkerton (1981), Meulbroek (1992), Bris (2005) and Pattitoni et al. (2015), tender offers are operations in which the risk of insider trading is particularly high. For example, during the time period covered by our analysis, 50 per cent of all insider-trading investigations started by the Italian National Commission for Companies and the Stock Exchange (Consob) concerned tender offers. In these operations, the abuse of privileged information can be very profitable. Moreover, 
focusing on this type of operations allows us to better identify the day when the operation is publicly announced, since the official announcement of a tender offer is rarely preceded by other press releases that can modify market expectations. In addition, analyzing these operations reduces the risk of unintentional leaks of information, since tender offers initiated by controlling shareholders are, in contrast with tender offers promoted by third parties, typically not preceded by lengthy negotiations. Finally, the effects of these operations on share prices generally start before and last until the day of the announcement: voluntary tender offers with the purpose of delisting initiated by controlling shareholders concern, by definition, minority shares and, thus, do not attract competing bids that may increase the offer price.

On the other hand, we chose to focus on the Italian market in order to analyze a civil law country, given the evidence of reduced effectiveness of insider-trading regulation in such countries. Additionally, outsider protection is considered limited in Italy (Melis 2000; Volpin 2002). As Volpin (2002: 62) notes, Italy is a country that 'features weak legal protection of creditors and shareholders, inefficient law enforcement, high ownership concentration'. This low protection may indeed simplify the econometric identification, as it worsens the problems caused by agency conflicts between outsiders and insiders. Moreover, restricting our attention to Italy allows us to bypass institutional heterogeneity, which would be otherwise difficult to control for.

Italy is, thus, an ideal setting for our analysis: given the extent and heterogeneity of the operations we analyze, our results contribute to the general debate on insider-trading regulation.

In the first step of our analysis, we exploit the quasi-experimental setting (Muravyev 2013, Quinn 2014) provided by the introduction of the MAD and test, by means of an event study, 
if the new regulation effectively discouraged insider-trading activities during tender offers. This analysis specifically aims at evaluating whether the introduction of the MAD produced appreciable effects on the magnitude of abnormal returns and volumes registered before tender offer announcement, when the information on the operation is still confidential. In a second step, based on regression and matching methods as well as poolability tests, we determine which corporate characteristics make insider trading more relevant and whether the MAD has changed the influence of these characteristics on the capacity of insiders to make profit. The latter analyses allow us to control for relevant idiosyncratic features of our data set, so as to facilitate the generalization of our conclusions on the effects of the MAD to other contexts.

The paper is organized as follows. Section 2 illustrates the changes in insider-trading regulation arising from the adoption of the MAD and the approval of the savings protection reform law (L. 28/12/05, n. 262) in Italy. Section 3 presents our empirical analysis and interprets the main findings considering the choice of the optimal amount of insider trading.

Section 4 provides some policy suggestions and concluding remarks. The Appendix A presents a case study that explains in detail the type of operations considered in our empirical analysis. Finally, the Appendix B provides further details on the MAD.

\section{Regulation on Insider Trading in Italy}

Our empirical analysis proposes a comparison between the pre- and post-MAD adoption periods in Italy. In this section, we illustrate the Italian institutional context and in particular how adopting the provisions of the European Directive modified the Italian regulation. 
Insider trading is considered a form of market abuse. The dense body of preventive and punitive provisions on insider trading is intended to ensure the integrity of financial markets and increase investor confidence.

Until recent revisions (Regulation 596/2014 (MAR) and Directive 2014/57/EU (MAD2), effective starting from 3 July 2016), European legislation on insider trading was based on the MAD (Directive 2003/6/EC of January 28, 2003), which sets forth the combined rules to contrast insider trading and market manipulation (together defined as market abuses). The adoption of the MAD was implemented according to the so-called Lamfalussy Procedure. This procedure provides for the cascading application of a first-level directive (the MAD) and a series of second-level directives (2003/124/EC, 2003/125/EC, 2004/72/EC) and European regulation (2003/2272/EC). The procedure also relies on the guidelines of the Committee of European Securities Regulators (CESR/04-505b, CESR/06-562b, CESR/09-219), now the European Securities and Markets Authority.

In Italy, the MAD was adopted by Law no. 62 of 18 April 2005, taking effect on 12 May 2005. This Law included changes to the Finance Act (Testo Unico della Finanza, TUF), the primary Italian regulatory source in matters of finance and financial markets. Because of these changes, Consob reformed the Issuers' Regulation (Regolamento Emittenti) and the Market Regulation (Regolamento Mercati). Insider-trading regulation in Italy has therefore undergone profound changes following the introduction of the MAD (Annunziata 2006): broadening of the definition of privileged information; legitimization of the delay in communication of privileged information; limitation of selective disclosure; new prevention measures; introduction of administrative penalties in addition to the penalties already in place; and reinforcing of the powers of Consob. Further details on these changes are given in Appendix B. 


\section{Empirical Analysis}

\subsection{Description of the Data Set}

Our initial data set includes the full population of Italian tender offers between January 1998 and March 2012 that, consistent with similar studies in the literature, meet three selection criteria. The examined tender offers are (i) voluntary, (ii) have the purpose of delisting, and (iii) are initiated by a shareholder directly or indirectly holding at least 20 per cent of the voting rights in the annual general meeting of shareholders and a share at least twice the one of the second largest shareholder (insider shareholder). The 20 per cent threshold is typically used in the literature on corporate control (La Porta et al. 1999; Faccio and Lang 2002). The condition of the largest shareholder's holding being at least twice the one of the second largest is related to the two-thirds quorum required by the Italian law for the control of the extraordinary shareholders' meeting (Bajo et al. 2011).

Based on the information found in the archives of the Italian stock exchange (Borsa Italiana S.p.A.), the application of these criteria leads to a data set covering 70 tender offers on a total of 84 shares (since some operations targeted multi-class stocks). This data set includes the entire population of cases that are useful for our analysis. All data are official, publicly available and verified through multi-step control procedures.

From this initial data set, we exclude the operations preceded by events that could have prepared the financial community for a potential tender offer $^{3}$ (and which would therefore make it impossible to determine whether abnormal market movements occurred), and those for which it was not possible to obtain the necessary data for the analysis. We point out that missing values are mostly attributable to nonsystematic misreporting by our data sources. For this reason, while we cannot completely rule out the risk of selection bias, we deem this risk 
unlikely to play a major role in our case. The final sample, which has a size consistent with similar works in the literature (e.g. Linciano, 2003; Pattitoni et al. 2015), includes 60 tender offers concerning 71 shares, which can be classified as follows: 56 ordinary shares, 13 savings shares (including 3 saving shares that could be converted into ordinary shares), and 2 preferred shares. About 65 per cent of the observations are in the Pre-MAD period.

Figure 1 shows the temporal distribution of the tender offers. The figure shows that the number of voluntary delistings typically increases during negative economic times. A first wave occurred in the two-year period between 2002 and 2003. This first wave may be due to the effects of the global slowdown in economic activity which began in 2001 following a series of negative events (from the delayed effects of the rise in oil prices to the terrorist attacks of September 11 and the bankruptcy of Enron), and became more pronounced in 2002 (in the period around the Argentine crisis). A second wave occurred in 2008, when the effects of the Great Recession, following the subprime mortgage crisis, were felt.

$<$ Figure 1 $>$

For each of the 71 observations of our data set, we have the following information concerning the characteristics of the firm undergoing the tender offer:

- the degree of ownership concentration, measured by the percentage of the share of the largest shareholder ( $m e a n=57 \%$; source: offer prospectus);

- a dummy variable indicating family firms (46\% of firms; source: offer prospectus);

- two dummy variables identifying industrial and financial firms (59\% and $15 \%$ of the firms respectively; source: offer prospectus); 
- a dummy variable indicating ordinary shares $(79 \%$ of shares; source: offer prospectus);

- target firm size, measured by the natural logarithm of market capitalization (mean = 5.26; source: Datastream);

- the degree of liquidity of the share, measured by the turnover ratio in the 250 days prior to the observation period (mean $=0.0024$; source: Datastream).

Table 1 contains descriptive statistics concerning all the variables.

\section{$<$ Table 1>}

\subsection{Methodology}

Our analysis intends to determine the effect of the introduction of the MAD on insidertrading activities. The occurrence of insider-trading activities is typically proven through careful investigation by the competent authorities (e.g., Consob).

However, abnormal changes in the prices and volumes of shares undergoing a tender offer during the days preceding the announcement may be considered as indications of transactions based on confidential information (Lin and Howe 1990; Bris 2005; Betzer and Theissen 2009; Madura and Marciniak 2014). For example, the Committee of European Securities Regulators (CESR), now the European Securities and Markets Authority, indicates the following possible indicators of insider trading (CESR/04-505b):

(u)nusual trading in the shares of a company before the announcement of price sensitive information relating to the company; transactions resulting in sudden and unusual changes in the volume of orders and shares prices before public announcements regarding the security in question. 
An event-study approach (Brown and Warner 1985; Ajinkya and Jain 1989; MacKinley 1997; Muravyev 2013; Kleinow et al. 2014) can be taken to determine the effects of a particular event on the trade prices and volumes of shares, and therefore represents an indirect method to identify the presence of insider trading. ${ }^{4}$ As Bris (2005: 309) notes, '(t)his approach circumvents the difficulties of drawing any empirical conclusion from the sole use of detected insider trading'.

To use the event-study approach, we need to identify the moment in which the privileged information enters the public domain (the so-called event date, indicated by convention as $t=$ 0). Based on the TUF, privileged information becomes public through the dissemination of a press release. Therefore, in our study the event date is that of the press release of the tender offer according to Article 102 (or 114) of the TUF or the following day if the press release was issued when the market was closed.

Once the date of the event is identified, we can calculate the abnormal returns (ARs) and volumes (AVs) that occur concurrently with the event. The abnormal return for the security $i$ at time $t$ is:

$$
A R_{i t}=r_{i t}-E\left(r_{i t}\right)
$$

where $A R_{i t}, r_{i t}$ and $E\left(r_{i t}\right)$ are the abnormal return, the observed return and the expected return (or normal return), respectively. To calculate the expected return, we use the marketadjusted model, the market model and the industry-adjusted model (Campbell et al. 1997; Cervellati et al. 2014). The three models produce similar results. Therefore, for the sake of simplicity, we report only the results of the industry-adjusted model, in which we estimate $E\left(r_{i t}\right)$ as the return of the sector stock index corresponding to the examined securities. ${ }^{5}$ The 
overall reaction of the market in the period prior to the communication of the tender offer is calculated by cumulating the abnormal returns (Jensen and Ruback 1983; Mikkelson and Ruback 1985; Sanders and Zdanowicz 1992; Bris 2005). For example, the cumulative abnormal return (CAR) in the five days preceding the notification of the tender offer is obtained by cumulating the corresponding abnormal returns. Once the ARs and the CARs are obtained for each of the firms in our sample, we calculate the average AR and the average CAR and test the statistical significance of the results. ${ }^{6}$

We perform a similar analysis on the volumes (measured using the turnover ratio). ${ }^{7}$ The abnormal volume for the security $i$ at time $t$ is:

$$
A V_{i t}=V_{i t}-E\left(V_{i t}\right)
$$

where $A V_{i t}, V_{i t}$ and $E\left(V_{i t}\right)$ are the abnormal volume, the observed volume, and the expected volume (or normal volume), respectively. To estimate the expected volume, we use the average turnover ratio of the security calculated in an estimation window of 250 days which range from $t=-275$ to $t=-26$ from the day of the event. The overall market reaction in the period prior to the notification of the tender offer is calculated by summing the abnormal volumes (CAV). Based on the AVs and the CAVs of the individual securities, we calculate the average AV and CAV and test the statistical significance of the results.

To conclude this section, it is worth mentioning that, in the case of insider trading, it is plausible to observe abnormal returns and volumes in the days preceding the announcement. However, as pointed out above, the presence of abnormal returns and volumes could also be attributable to the capacity of the market to anticipate the event and/or to rumors circulating 
in the media. To consider abnormal returns and volumes as a true indicator of insider trading, we will therefore need to control for these alternative explanations in our empirical analysis.

\subsection{Market Reaction in the Days Preceding the Event}

\subsubsection{Event-study Results}

In this section, we assess whether the introduction of the MAD reduced the size of abnormal returns and volumes before the announcement of the tender offer.

Figure 2 shows the CARs and the AVs in the days around the announcement of the tender offer in the pre- and post-MAD periods. The CARs and the AVs in the pre-MAD period do not seem significantly different from those in the post-MAD period: the series of pre- and post-MAD CARs almost overlap, and the same applies to the series of pre- and post-MAD AVs. This descriptive analysis seems to suggest that the introduction of the MAD did not produce appreciable effects on the size of abnormal returns and volumes recorded before the announcement.

$<$ Figure $2>$

These results are investigated more in depth in Table 2, where we compare the CARs and the CAVs from the pre-MAD period with those from the post-MAD period. To calculate the CARs and CAVs, we set the observation intervals at $[-25,-1]$ and $[-5,-1]$ from the day of the event. ${ }^{8}$

$<$ Table 2>

The results show significant CARs in both the pre- and post-MAD periods. However, the difference between the pre- and post-MAD CARs is not statistically significant. These results 
seem to confirm what already observed in Figure 2: the introduction of the MAD does not seem to have reduced the capacity to achieve abnormal returns before the announcement.

However, with regard to the abnormal volumes, our results do not show significant CAVs either in the pre- or post-MAD periods (excluding the case of post-MAD CAVs in the interval $[-5,-1])$. The presence of significant CARs and non-significant CAVs seems to suggest that the transactions generating abnormal returns are limited in magnitude. This evidence is consistent with the 'stealth trading hypothesis' (Barclay and Warner 1993; Ryu, 2012), according to which potential insider traders perform small transactions in order not to reveal their confidential information.

As mentioned in the previous section, the presence of abnormal returns in the period preceding the announcement does not necessarily imply insider trading, for example because of the market's capacity to anticipate the event and/or of rumors. To mitigate this risk, we present additional results in Table 3.

$<$ Table 3>

We first calculate abnormal returns and volumes corresponding to the day of the event. The presence of significant ARs and AVs on the day of the announcement suggests that the communication of the tender offer is an unexpected event for the majority of investors.

We then recalculate the CARs in the period preceding the announcement, excluding cases that could be influenced by rumors. In particular, we exclude observations related to firms on which articles referring to a potential tender offer appeared in the main national financial newspapers (Il Sole 24 Ore and MF-Milano Finanza) within the five days preceding the official announcement. After excluding 15 cases from the sample, we do not find significant changes to the CARs. In the light of these results, it is therefore plausible that the presence of 
CARs in the days prior to the communication is attributable (at least in part) to insider trading.

As shown by Bris (2005), insider-trading regulation implies an increase of the reaction in the day of the announcement and a reduction in the prior days. A result that our analysis seems to reject. Therefore, although the adoption of the MAD formally reinforced insider-trading regulation, the price dynamics in the days preceding the announcement of the tender offer seem to contain, even post-MAD, indications of insider trading that are very similar to those in the pre-MAD period.

It should also be said that, as pointed out by Bhattacharya and Daouk (2002), the effects of insider-trading regulation should not be assessed from the time of their introduction, but from the time of their first actual application. Therefore, as an additional robustness check, we report in Table 3 updated results in which we include in the post-MAD subsample only observations after 2005 (and not 2004) to allow for a one-year lag in application. Our findings are confirmed.

To investigate the matter even further, we estimate the profits of insider trading in the 25 days prior to the announcement of the tender offer, adapting the Bris (2005) method to our context. The results presented in Table 4 show statistically significant and larger post-MAD profits. However, these are never statistically different from the pre-MAD profits, consistent with previous results.

$<$ Table 4>

In summary, our results suggest that the MAD is ineffective against this specific phenomenon. This result seems unjustified in the light of the regulation changes introduced 
by the MAD and documented in Section 2 and Appendix B. However, the theoretical analysis in the following section could help explaining this phenomenon.

\subsubsection{Theoretical Considerations}

Let us imagine that the potential insider weighs the benefits and the expected costs when selecting the magnitude of the insider-trading operation. Suppose that the benefits are an increasing and concave function $B(q)$ of the amount of insider trading, with $B^{\prime}(q)>0$, and $B^{\prime \prime}(q)<0$. Let us assume also that the cost of being caught by the authorities is proportional (through the constant $\theta$ ) to the amount of insider trading $C(q)=\theta q$. Then, if we indicate with $\pi$ the probability of being caught, the expected costs of insider trading are equal to $\pi C(q)=\pi \theta q$, and the economic problem of the potential insider is the following:

$\max _{q} B(q)-\pi \theta q$

the maximum of which is implicitly determined by the condition $B^{\prime}\left(q^{*}\right)=\pi \theta \cdot{ }^{9}$ A simple comparative statics exercise reveals that the optimal amount of insider trading decreases with the increase of the (ex ante) penalty and with an increase in the probability of being caught (ex post):

$\frac{\partial q^{*}}{\partial \theta}=\frac{\pi}{B^{\prime \prime}\left(q^{*}\right)}<0$, and $\frac{\partial q^{*}}{\partial \pi}=\frac{\theta}{B^{\prime \prime}\left(q^{*}\right)}<0$

Therefore, it may be expected that increasing the size of the penalty (increasing $\theta$ ) reduces the amount of insider trading, and, in this sense, the MAD represents a step forward from previous regulation. The majority of the new elements introduced by the MAD, as discussed 
in Section 2 and Appendix A, are geared towards increasing $\theta$. On the other hand, the success of insider-trading regulation requires the presence of effective ex post monitoring activities by competent bodies. If due to the objective difficulties in investigating cases of insider trading the probability of being caught is relatively low (or close to zero), the ex ante punitive measures may be only partially effective (or even non-effective, since in Equation (4) $\pi \rightarrow 0$ implies $\partial q^{*} / \partial \theta \rightarrow 0$ ). When the probability of being caught is relatively low, the only concern of the insiders would be 'masking' their operations (a result consistent with the aforementioned 'stealth trading hypothesis').

In addition, a reduction in per-operation resources for monitoring (or an increase in monitoring costs) reduces monitoring activities, and therefore the probability of being caught. For example, in the context of our analysis, the aforementioned broadening of the definition of privileged information may have increased the number of potential cases to monitor and, keeping total resources fixed, reduced per-operation resources and, in turn, the number of actual cases investigated. ${ }^{10}$ In our simple model, this reduction in resources translates in a decrease of $\pi$ (say from $\pi_{\text {pre }}$ to $\pi_{\text {post }}$, with $\pi_{\text {post }}<\pi_{\text {pre }}$ ), which may compensate the effect of the increase of $\theta$ (say from $\theta_{\text {pre }}$ to $\theta_{\text {post }}$, with $\theta_{\text {post }}>\theta_{\text {pre }}$ ). In particular, the increase of $\theta$ is completely vanished if the probability of being caught following the introduction of the law is reduced to:

$$
\pi_{\text {post }}=\pi_{\text {pre }} \frac{\theta_{\text {pre }}}{\theta_{\text {post }}} .
$$

In this case, a form of 'crowding-out effect' occurs, which means that the solution of the problem in Equation (3) remains unchanged. 
Lastly, if we consider, as a theoretical curiosum, the limiting case of an increase in penalties met by an increase in monitoring costs (and therefore by a reduction in $\pi$ ), an increase of $\theta$ may be followed by an increase in the optimal amount of insider trading. In fact, the comparative statics regarding the problem in Equation (3) in the event that $\pi$ depends on $\theta$ becomes:

$\frac{\partial q^{*}}{\partial \theta}=\frac{\pi+\theta \partial \pi / \partial \theta}{B^{\prime \prime}\left(q^{*}\right)}$

where for $\pi+\theta \partial \pi / \partial \theta<0$, we obtain $\partial q * / \partial \theta>0 .{ }^{11}$

In the light of both the empirical results and this discussion, we believe that the apparent ineffectiveness of the MAD is attributable, at least in part, to ex post monitoring issues (Bajo and Petracci 2006; Pattitoni et al. 2013).

\subsection{The Effect of Corporate Characteristics}

\subsubsection{Regression and Matching Results}

The results of our event study show significant CARs in both the pre- and post-MAD periods. However, their difference is not statistically significant, suggesting a limited role of the MAD in reducing abnormal returns. A potential problem with the univariate approach of our event study is that, when comparing results pertaining to different subsamples, any result, either significant or non-significant, may be due to subsample heterogeneity (in our case, differences in the characteristics of the firms in the pre- and post-MAD periods) (Angrist and Pischke, 2008). 
Thus, in this section we exploit the quasi-experimental setting provided by the introduction of the MAD and check whether idiosyncratic features of our sample drive the negligible effect of this regulation change in terms of unconditional mean, suggesting that the MAD might be effective after controlling for corporate characteristics.

Table 5 contains descriptive statistics concerning corporate characteristics, distinguishing between the pre- and post-MAD periods. Encouragingly, the difference tests between the two periods reveal a certain degree of homogeneity. The only significant difference concerns the proportion of ordinary shares. However, this difference is probably due to the structural reduction in the number of savings shares and preferred shares compared to ordinary shares, which interested Italy during the observed period (Mancinelli and Ozkan 2006). Even though data are more numerous in the Pre-MAD period, the fact that firm characteristics are balanced across the two subsamples facilitates econometric comparison and reinforces the conclusions of our univariate analysis (Angrist and Pischke, 2008).

\section{$<$ Table 5>}

Despite the two subsamples being quite balanced, we nevertheless perform, as a further robustness check, a multivariate analysis to estimate the effect of the MAD on abnormal returns after controlling for corporate characteristics. In particular, we consider two approaches. The first approach is based on a regression analysis, where the dependent variable is the ratio $C A R(-5,-1) / C A R(-5,0) .{ }^{12}$ Given that $C A R(-5,-1)$ and $C A R(-5,0)$ typically have a concordant sign, and that the majority of market reaction occurs in $t=0$ (so that $|C A R(-5,0)|>|C A R(-5,-1)|$, this variable (henceforth, CAR-ratio) may be interpreted as an indicator of the part of the total market reaction that is attributable to trading activities made before the announcements. An advantage of this variable over the simple $C A R(-5,-1)$ is that it corrects, by putting together two CARs referring to the same event, for the potential 
effect of the tender offer price on the size of the CARs, and for potential unexplained heterogeneity (Linciano (2003) uses a similar ratio).

Indicating the CAR-ratio with $y_{i}$ and the vector of explanatory variables (described in Section 3.1 and including a constant term) with $\mathbf{x}_{i}$, the general model for our analysis is:

$$
y_{i}=\mathbf{x}_{i}^{\prime} \boldsymbol{\beta}+\delta p_{i}+\varepsilon_{i}
$$

where $p_{i}$ is a dummy variable equal to 1 for the post-MAD period, $\varepsilon_{i}$ is a zero-mean stochastic error term, while $\delta$ and $\boldsymbol{\beta}$ denote to coefficients to be estimated. In particular, the coefficients included in the vector $\boldsymbol{\beta}$ measure the effect of the corporate characteristics on the CAR-ratio, and $\delta$ measures the effect of the MAD after controlling for these characteristics.

The second approach is based on matching estimators (Angrist and Pischke, 2008; Greene, 2011), where we compare CAR-ratios of cases in the pre- and post-MAD subsamples that are as similar as possible in terms of control variables. To do so, we use two methods based on similarity measures: nearest-neighbor and propensity-score matching. In nearest-neighbor matching, we match cases on the basis of their Mahalanobis distance computed with respect to the control variables. Then, we calculate the average difference between the CAR-ratios of the matched cases (i.e. the average treatment effect). In propensity-score matching, matches are obtained by estimating logit models for the post-MAD dummy variable, using the control variables as independent variables.

In Table 6, we show the results of the regression analyses. We estimate two models. Model [1] presents the estimates for the full model described in Equation (7). Model [2] is a restricted model chosen by means of a general-to-specific selection procedure (Verbeek 
2012) retaining only the control variables with a p-value lower than 0.2 (Candela et al., 2015). The results of Models [1] and [2] suggest that, even after controlling for corporate characteristics (which, however, are largely accounted for by our CAR-ratio definition and thus not significant), the effect of the MAD on abnormal returns is not significant, casting further doubts on its effectiveness. The only significant control variable is ownership concentration: the CAR-ratio tends to be lower for concentrated firms, as discussed later on.

$<$ Table 6>

Table 7 shows the results based on matching estimators. They substantially confirm those based on the regression analyses, as the average effect associated with the introduction of the MAD is not significant. After controlling for differences in the observable characteristics of the firms in the pre- and post-MAD subsamples, the results are consistent with the view that the introduction of the MAD did not produce appreciable effects.

\section{$<$ Table 7>}

\subsubsection{Poolability Test and Interactions}

In the previous sections, we hypothesized that the apparent ineffectiveness of the MAD is attributable, at least in part, to the reduced effectiveness of the monitoring activities. In this section, we wonder if it is possible to direct the competent bodies to particular firms in order to make monitoring activities more efficient (and therefore less costly) and improve (indirectly) the effectiveness of insider-trading regulation. In particular, we wonder if the MAD has made earning profits more difficult at least for certain categories of firms (for example family or financial firms) given that, on the whole, its effectiveness is questionable. 
To answer this question, we perform a regression-based poolability test (Patuelli et al. 2010; Verbeek 2012) to check for subsample stability of the estimated coefficients with respect to the pre-/post-MAD subdivision. The general model for our poolability test is:

$$
y_{i}=\mathbf{x}_{i}^{\prime} \boldsymbol{\beta}+p_{i} \mathbf{x}_{i}^{\prime} \boldsymbol{\delta}+\varepsilon_{i},
$$

where $y_{i}, \mathbf{x}, p_{i}$ and $\varepsilon_{i}$ are defined as in Equation (7), and $\boldsymbol{\beta}$ and $\boldsymbol{\delta}$ are vectors of coefficients to be estimated. In particular, the coefficients included in $\boldsymbol{\beta}$ measure the effect of corporate characteristics on the CAR-ratio in the pre-MAD period. The coefficients included in $\boldsymbol{\delta}$ measure the deviations from the related coefficients given in $\boldsymbol{\beta}$ due to the introduction of the MAD. Finally, by summing $\boldsymbol{\beta}$ and $\boldsymbol{\delta}$, we obtain the effects of the corporate characteristics on the CAR-ratio in the post-MAD period. The poolability test consists of assessing the joint significance of the coefficients included in the vector $\boldsymbol{\delta}$, in order to determine if the introduction of the MAD had consequences for firms along specific dimensions.

We present related results in Table 8 . Model [5] presents the estimate for the full model described by Equation (8). In the upper panel of the table, we present the estimates of the elements of $\boldsymbol{\delta}$, while in the lower panel of the table, we present the ones for $\boldsymbol{\beta}$. The poolability test presented at the bottom of Model [5] is not significant, and suggests that on average the effect of the explanatory variables on the CAR-ratio is the same in the pre- and post-MAD periods. However, it is worth noting that before the introduction of the MAD, ownership concentration had a negative effect on CAR-ratio, while in the post-MAD period, firm size has a positive effect on CAR-ratio. The other variables are not significant. 
Given the limited number of observations in our data set, which, however, represents the full population of cases, we estimated, as a robustness check, restricted models to improve efficiency with respect to Model [5]. Models [6] and [7] are obtained by using two different general-to-specific selection procedures. In Model [6], we eliminate each pair of variables (pre- and post-MAD) with a p-value greater than 0.2. Therefore, in this model a variable and its interaction with the post-MAD dummy are considered as a single unit and can only be eliminated together. In Model [7], we eliminate all variables with a p-value greater than 0.2.

Models [6] and [7] essentially confirm the findings of Model [5], in particular with regard to the negative effect of ownership concentration in the pre-MAD period and, at least in Model [7], the positive effect of firm size in the post-MAD period. Model [7] adds to these results that the introduction of the MAD acts as moderator of the negative effect of concentration: here, the interaction between the concentration variable and the post-MAD dummy has a positive coefficient approximately equal to the absolute value of the coefficient for the concentration variable $(2.3493 \cong|-2.4766|)$. This implies that the effect of concentration in the post-MAD period is approximately null. Furthermore, the negative and significant coefficient of the post-MAD dummy variable suggests that, in this model, market reaction in the post-MAD period seems reduced.

\section{$<$ Table 8>}

It is possible to interpret these results in the light of the changes introduced by the MAD, and particularly of the type of operation considered in our analysis. The negative coefficient of the post-MAD dummy variable may be attributed to the fact that the changes introduced by the MAD may have concerned certain categories of firms more than others. In particular, the positive effect of size in the post-MAD period may be justified by the fact that some of the changes introduced by the law (e.g. the stricter requirements in terms of transparency) made 
it relatively more difficult to earn profits on less capitalized firms. ${ }^{13}$ We may interpret the result regarding the vanished effect of firm concentration in a related vein. In concentrated firms, the possibility of earning profits is partially precluded by the fact that the controlling shareholder who has initiated the tender offer holds a larger share of capital (thereby limiting the number of shares that can actually be traded by the insider). In terms of the choice problem of the optimal amount of insider trading, described in Equation (3), this limit translates to a constraint on the optimal amount of insider trading. The problem becomes:

$$
\max _{q} B(q)-\pi \theta q \quad \text { sub } \quad q \leq q_{\max }
$$

Let us suppose that in the pre-MAD period the constraint $q \leq q_{\max }$ is active. Therefore, in the case of non-concentrated firms, the problem of the insider is the same as the unconstrained one in Equation (3), and the optimal choice is $q_{p r e}^{*}$. On the other hand, with respect to concentrated firms, the problem of the insider is as in Equation (9), and the optimal choice (assuming an active constraint ${ }^{14}$ ) is $q_{\max }<q_{p r e}^{*}$. Since market reaction is positively related to the amount of the insider-trading operations, at the empirical level this result implies a greater reaction for non-concentrated firms and, therefore, a negative relationship between firm concentration and CAR-ratio.

In the post-MAD period, the increase in the magnitude of penalties results in a conditional reduction in the optimal amount of insider trading. Thus, in this case, the solution of the problem in Equation (3) is $q_{\text {post }}^{*}<q_{\text {pre }}^{*}$. If we hypothesize that $q_{\text {post }}^{*}<q_{\max }$, the constraint of the problem in Equation (9) is no longer active, and the optimal choice, equal to $q_{\text {post }}^{*}$, is the same for concentrated and non-concentrated firms. At the empirical level, this result implies a null relationship between firm concentration and CAR-ratio. 
Figure 3 provides a graphic representation of the problem: in the pre-MAD period, $q_{\max }<q_{p r e}^{*}$; in the post-MAD period, the marginal cost curve of insider trading moves upwards, and $q_{\text {post }}^{*}<q_{\max }$. Therefore, in the pre-MAD period, the choice of the optimal amount of insider trading is different for concentrated $\left(q_{\max }\right)$ and non-concentrated $\left(q_{\text {pre }}^{*}\right)$ firms; in the post-MAD period, the choice is the same $\left(q_{p o s t}^{*}\right)$ for both concentrated and nonconcentrated firms.

$<$ Figure $3>$

\section{Concluding Remarks}

Our empirical analysis examined a sample of voluntary tender offers with the purpose of delisting initiated by controlling shareholders. We aimed to determine whether the introduction of the MAD resulted in appreciable differences in the profits achieved before the announcement of the operation and which can be attributed, at least in part, to insider-trading activities.

Our results, corroborated by several robustness checks, show that the abnormal returns and volumes recorded in the pre- and post-MAD periods do not significantly differ, suggesting at least a partial ineffectiveness of the MAD. The results of regression and matching estimators, which exploits the quasi-experimental setting provided by the introduction of the MAD and allow us to increase the generalization potential of our analysis, confirm this main finding after controlling for idiosyncratic features of our sample.

Our results would seem unjustified in the light of the considerable regulation changes introduced by the MAD. However, some theoretical considerations seem to suggest that the problem is to be found in the reduced effectiveness of the ex post monitoring activities on the 
part of the competent bodies. Due to resource rationing and to objective limits in proving insider trading, the effect of the ex ante increase in punitive actions is plausibly vanished ex post by the crowding-out effect of the reduction in the probability of being caught, which may be further intensified by forms of stealth trading.

In this context, improving the efficiency of the monitoring activities of competent bodies becomes crucial. Our analysis provides suggestions in this direction by finding that certain corporate characteristics can influence the capacity of insiders to achieve profits. For example, market reactions that precede tender offer announcements tend to be greater for larger firms, on which monitoring activities should then be intensified. Moreover, following the introduction of the MAD, the effect of ownership concentration seems to have become irrelevant, probably due to an implicit constraint on the optimal amount of insider trading, which characterized concentrated firms before the reform.

Further research could expand these results by considering other markets. Although the Italian market may be considered as an ideal context for our empirical analysis due to its structural characteristics, research on other European countries could check for further implications of the model, in the context of quasi-experiments (Dharmapala and Khanna 2013). These implications could be useful to stimulate further debate regarding the changes brought about by the MAD and, more in general, to develop an effective insider-trading regulation. Finally, after the recent changes made to the MAD (MAR and MAD2) are fully enforced and data become available, future studies may be able to test how (and if) these changes have been effective in solving the problems of MAD. 


\section{Appendix A. A Voluntary Tender Offer with the Purpose of Delisting: The Case of Benetton}

In order to better understand the type of financial operations considered in this study, this Appendix presents of a case study involving the delisting of Benetton.

On 31 January 2012, at 1:58 p.m., Edizione S.r.l. announced the delisting of the subsidiary Benetton, one of the symbols of 'made in Italy' in fashion, listed on the market since 1986. At the request of Edizione S.r.l., trading on Benetton shares was suspended (suspension maintained until 1 February 2012). Each Benetton share at that time was worth $€ 4.05$ for a total capitalization of $€ 740$ million. Considering the reduction in the listing price of the security in $2012(-40 \%)$ and the drastic decrease in profits, the decision to delist was evaluated positively by financial analysts. Such decision was motivated by the need to regain total control of the company to determine its future "without needing to take into account non-controlling interests' (Filippetti 2012a).

On 1 February 2012, at 7:27 p.m., Edizione S.r.l. officially communicated the details of the tender offer. The estimated cost of the operation, assuming a positive response on the part of all of the minority shareholders, was equal to $€ 276$ million. The offer price of $€ 4.60$ included an increase of 40 per cent over the average price of the security in the last month and 60 per cent over the average price of 2011 (Filippetti 2012b), therefore providing an advantage to those who had recently acquired Benetton shares. However, for longer-term investors the tender offer probably entailed a loss: in 1986 , the shares were set at $€ 4.65$, and in October 2009 they were quoted at $€ 7.55$ (Liera 2012).

At the same time of the announcement of the offer, Consob initiated investigations on trading that had taken place on the Benetton shares before the announcement. On 30 and 31 January 
2012, the doubling in the number of traded Benetton shares and the strong increase in price $(+19.82 \%)$ led the parent company Edizione S.r.l. to communicate to the market the company's intention to delist, and to request suspension of trading on Benetton while awaiting the details of the tender offer. The announcement of the tender offer resulted in a consistent increase in trading of the security and an increase in prices: on the first open market day following the announcement (2 February 2012), Benetton shares witnessed a 17 per cent increase, coming in at $€ 4.70$, a little above the offer price. Figure A1 presents the changes in prices and volumes in the days around the announcement.

$<$ Figure A1>

In the light of the abnormal movements in prices and volumes in the days preceding the official announcement of the operation, Consob decided to determine (i) whether insider trading occurred; (ii) who initiated the trading, and (iii) if the trading occurred among a limited number of operators. Similar to the Consob investigation, our empirical analysis intends to identify indications of insider trading by noting the abnormal movements in prices and volumes prior to the official announcement of the delisting operation. We use the word 'indications' because abnormal changes in prices and volumes can be caused by factors other than insider trading: for example, the capacity of the market to anticipate the event and/or the circulation of rumors. In the Benetton case, rumors circulated in the days preceding the tender offer announcement (being even reported by Bloomberg) of a merger between the company and Zara, which Benetton officially denied at 12 p.m. on 31 January 2012. 


\section{Appendix B. Main Effects of the MAD on the Italian}

\section{Insider-Trading Regulation}

In this Appendix, we summarize the main changes arising from the adoption of the MAD. We make no claims of completeness, since we focus on aspects related to insider trading only:

- Broadening of the definition of privileged information. The MAD broadened the definition of 'privileged information'. The new definition extends to events or circumstances that have not yet occurred, but which could reasonably occur. This extension requires that listed firms pay greater attention to the process of formation, circulation, and communication to third parties of privileged information in order to avoid market abuse.

- Legitimization of the delay in communication of privileged information. The public communication of privileged information may be postponed when the disclosure of the information could hurt the legitimate interests of the listed firms, provided the delay does not mislead the public. However, the firm must guarantee the confidentiality of the privileged information for the entire period of the delay.

- Limitation of selective disclosure. The MAD limits the risk that privileged information being disclosed only to certain parties (selective disclosure), permitting disclosure to third parties only through 'the normal course of the exercise of his employment, profession, or duties.' If the third party is not bound by obligations of confidentiality, the privileged information must be immediately provided to the public in order to restore the conditions of parity of information. The disclosure to the public 
must be simultaneous in the event of intentional selective disclosure and "without delay' in case of unintentional selective disclosure.

- New prevention measures. The MAD introduced new prevention measures intended to promote traceability of offenses and transparency of operations conducted by primary insiders, and refined the existing measures. In particular, listed firms must create a record of persons with access to privileged information. This record must be regularly updated. In addition, intermediaries are obliged to report operations that could have originated in insider trading or market manipulation. Reporting is made only to the competent authorities, without informing the subjects on behalf of whom the operations were performed.

- Introduction of administrative penalties in addition to the penalties already in place. One of the most innovative elements of the MAD is the addition of further administrative penalties. Because of Law No. 262/2005, following the adoption of the MAD, the amounts of administrative penalties increased fivefold: from a minimum of $€ 60,000$ to a maximum of $€ 15,000,000$. The administrative penalties were also required for secondary insiders and, more generally, anyone capable of recognizing the 'privileged' nature of the acquired information.

- Reinforcing of the powers of Consob. The MAD provided increased investigation and verification powers to Consob, which also has the option of directly applying administrative penalties.

\section{References}

Allingham M. G., Sandmo A. 1972. "Income tax evasion: A theoretical analysis," 1 Journal of Public Economics 323-338. 
Ajinkya B.B., Jain P.C. 1989. "The behaviour of daily stock market trading volume," 11 Journal of Accounting and Economics 331-359.

Angrist, J. D., Pischke, J. S. 2008. Mostly harmless econometrics: An empiricist's companion. Princeton, NJ: Princeton University Press.

Annunziata F. 2006. Abusi di mercato e tutela del risparmio. Torino, Italy: G. Giappichelli Editore.

Baccolini R., Ferretti R., Lusignani G. 1991. "Informazioni privilegiate e dinamica delle quotazioni alla borsa di Milano," 2 Finanza Imprese e Mercati 143-170.

Balducci R., Candela G., Scorcu A. 2001. Introduzione alla politica economica. Bologna, Italy: Zanichelli.

Bajo E., Barbi M., Bigelli M., Hillier D. 2011. “The role of institutional investors in publicto-private transactions," 37 Journal of Banking \& Finance 4327-4336.

Barclay M. J., Warner J. B. 1993. "Stealth trading and volatility: Which trades move prices?," 34 Journal of Financial Economics 281-305.

Bajo E., Petracci B. 2006. "Do what insiders do: Abnormal performances after the release of insiders' relevant transactions," 23 Studies in Economics and Finance 94 - 118

Bhattacharya U., Daouk, H. 2002. "The world price of insider trading," 57 Journal of Finance 75-108.

Becker G. S. 1968. "Crime and punishment: An economic approach," 76 The Journal of Political Economy 169-217. 
Beny N. L. 2008. "Do Investors in Controlled Firms Value Insider Trading Laws? International Evidence," 4 Journal of Law, Economics \& Policy 267-310.

Betzer A., Theissen E. 2009. "Insider trading and corporate governance: the case of Germany,” 15 European Financial Management 402-429.

Boehmer E., Musumeci J., Poulsen A.B. 1991. "Event-study methodology under conditions of event-induced variance," 30 Journal of Financial Economics 253-72.

Bris A. 2005. "Do Insider Trading Laws Work?," 11 European Financial Management 267312.

Brown S.J., Warner J.B. 1985. "Using Daily Stock Returns: The Case of Event Studies,” 14 Journal of Financial Economics 3-31.

Campbell J.Y., Lo A.W.C., MacKinlay A.C. 1997. The econometrics of financial markets. Princeton, NJ: Princeton University Press.

Candela G., Castellani M., Pattitoni P., Di Lascio F.M.L. 2015. “On Rosen’s and Adler’s hypotheses in the modern and contemporary visual art market," Empirical Economics $1-23$.

Cervellati E.M., Ferretti R., Pattitoni P. 2014. "Market Reaction to Second-Hand News: Inside the Attention Grabbing Hypothesis," 46 Applied Economics 1108-1121.

CESR. 2004. "Market Abuse Directive. Level 3 - first set of guidance and information on the common operation of the Directive," CESR/04-505b.

Clarkson P. M., Joyce D., Tutticci I. 2006. "Market reaction to takeover rumour in Internet Discussion Sites," 46 Accounting and Finance 31-52. 
Consob. 2005. «Esempi di manipolazione del mercato e di operazioni sospette indicati dal Committee of European Securites Regulators (CESR) nel documento 'Market Abuse Directive. Level 3 - first set of guidance and information on the common operation of the Directive'. Istruzioni per la segnalazione di operazioni sospette». Comunicazione n. DME/5078692, November 2005

Dharmapala D., Khanna V. 2013. "Corporate governance, enforcement, and firm value: evidence from India,” 29 Journal of Law, Economics, and Organization 1056-1084.

Engelen, P. J. 2006. "Difficulties in the criminal prosecution of insider trading-A clinical study of the Bekaert case,” 22 European Journal of Law and Economics, 121-141.

Faccio M., Lang L.H.P. 2002. "The ultimate ownership of Western European corporations," 65 Journal of Financial Economics 365-395.

Filippetti S. 2012a. "Le scelte della seconda generazione," Il Sole 24 Ore, February 1.

Filippetti S. 2012b. "Edizione lancia l'Opa su Benetton a 4,6 euro. Delisting per il rilancio," Il Sole 24 Ore, February 2.

Forbes W. 2013. "No conflict, no interest: on the economics of conflicts of interest faced by analysts," 35 European Journal of Law and Economics 327-348.

Greene W.H. 2011. Econometric analysis, 7th ed. New York, NY: Prentice Hall

Jensen M. C., Ruback R. S. 1983. "The market for corporate control. The scientific evidence," 11 Journal of Financial Economics, 5-50.

Keown A. J., Pinkerton J. M. 1981. "Merger announcements and insider trading activity: an empirical investigation,” 36 Journal of Finance, 855-69. 
Kleinow J., Nell T., Rogler S., Horsch A. 2014. "The value of being systemically important: event study on regulatory announcements for banks," 24 Applied Financial Economics 1585-1604.

Linciano, N. 2003. "The effectiveness of insider trading regulation in Italy. Evidence from stock-price run-ups around announcements of corporate control transactions," 16 European Journal of Law and Economics 199-218.

La Porta R., Lopez-de-Silanes F., Shleifer A. 1999. "Corporate ownership around the world," 54 Journal of Finance, 471-517.

Liera M. 2012. "Se il rischio del cassettista è pari a quello di chi fa trading," Il Sole 24 Ore, February 5.

Lin J.C., Howe J. S. 1990. "Insider trading in the OTC market," 45 Journal of Finance 12731284.

MacKinley C.A. 1997. "Event Studies in Economics and Finance," 35 Journal of Economic Literature 13-39.

Madura J., Marciniak M. 2014. "Characteristics of takeover targets that trigger insider trading investigations," 24 Applied Financial Economics 1-18.

Madura J., Ngo T., Susnjara J. 2014. "Information leakages and the costs of merging in Europe,” 24 Applied Financial Economics 515-532.

Mancinelli, L., Ozkan, A. 2006. "Ownership structure and dividend policy: Evidence from Italian firms," 12 European Journal of Finance 265-282. 
Melis A. 2000. "Corporate governance in Italy," 8 Corporate Governance: An International Review 347-355.

Meulbroek L. K. 1992. “An empirical analysis of illegal insider trading,” 47 Journal of Finance 1661-99.

Mikkelson W. H., Ruback R. S. 1985. "An empirical analysis of the interfirm equity investment process," 14 Journal of Financial Economics 523-53.

Muravyev A. 2013. "Investor Protection and the Value of Shares: Evidence from Statutory Rules Governing Variations of Shareholders' Class Rights in an Emerging Market," 29 Journal of Law, Economics, and Organization 1344-1383.

Pacini C., Marlett D.C. 2001. "The market valuation and trading volume effects on the creation of Florida Hurricane Catastrophe Fund on property-liability insurers," 28 Journal of Business Finance \& Accounting 407-445.

Padilla A. 2011. "Should the Government Regulate Insider Trading?," 22 Journal of Libertarian Studies 379-398.

Pattitoni P., Petracci B., Spisni M. 2013. "Insider trading and blackout periods: evidence from Italy," 20 Applied Economics Letters 1625-1629

Pattitoni P., Petracci B., Spisni M. 2015. “'Hit and Run' and 'Revolving Doors': evidence from the Italian stock market," 19 Journal of Management \& Governance 285-301.

Patuelli R., Vaona A., Grimpe C. 2010. "The German East-West divide in knowledge production: an application to nanomaterial patenting," 101 Tijdschrift voor Economische en Sociale Geografie 568-582. 
Quinn, S., 2014. "The Value of Corporate Governance for Bank Finance in an Emerging Economy: Evidence from a Natural Experiment," 30 Journal of Law, Economics, and Organization 1-38.

Rose, C., Søpstad, N. 2015. "Reactions to corporate insider's transactions: Do legal stock market disclosure rules have an impact?," 40 European Journal of Law and Economics, 247-272.

Ryu D. 2012. "The effectiveness of the order-splitting strategy: an analysis of unique data," 19 Applied Economics Letters 541-549.

Sanders R.W. Jr., Zdanowicz J. S. 1992. "Target firm abnormal returns and trading volume around the initiation of change in control transactions," 27 Journal of Financial and Quantitative Analysis 109-129.

Verbeek M. 2012. A guide to modern econometrics 4th ed. Chichester, England: Wiley.

Volpin, P. 2002. "Governance with poor investor protection: evidence from top executive turnover in Italy," 64 Journal of Financial Economics 61-90. 
Table 1. Descriptive statistics

\begin{tabular}{|c|c|c|c|c|}
\hline Variable & Mean & SD & Min & Max \\
\hline Post-MAD & 0.3521 & 0.4810 & & \\
\hline Ownership concentration & 0.5740 & 0.2050 & 0.1469 & 0.9335 \\
\hline Family firm & 0.4648 & 0.5023 & & \\
\hline Industrial firm & 0.5915 & 0.4950 & & \\
\hline Financial firm & 0.1549 & 0.3644 & & \\
\hline Common stock & 0.7887 & 0.4111 & & \\
\hline Firm size $(\log )$ & 5.2611 & 0.8083 & 3.7214 & 7.6000 \\
\hline Liquidity & 0.0024 & 0.0028 & 0.0001 & 0.0126 \\
\hline
\end{tabular}

Table 2. Event study and pre- and post-MAD difference tests

\begin{tabular}{l|ccc|ccc|ccc}
\hline & \multicolumn{3}{|c|}{ Pre-MAD } & \multicolumn{3}{c|}{ Post-MAD } & \multicolumn{3}{c}{ Difference } \\
Variable & Coef & SE & Sign & Coef & SE & Sign & Coef & SE & Sign \\
\hline CAR $(-25,-1)$ & 0.0707 & 0.0172 & $* * *$ & 0.0955 & 0.0204 & $* * *$ & 0.0247 & 0.0266 \\
CAR $(-5,-1)$ & 0.0511 & 0.0094 & $* * *$ & 0.0618 & 0.0117 & $* * *$ & 0.0107 & 0.0150 \\
CAV $(-25,-1)$ & 0.0190 & 0.0123 & & 0.0129 & 0.0148 & & -0.0061 & 0.0193 \\
CAV $(-5,-1)$ & 0.0136 & 0.0092 & & 0.0095 & 0.0046 & $* *$ & -0.0041 & 0.0103
\end{tabular}

$* \mathrm{p}<0: 10, * * \mathrm{p}<0: 05, * * * \mathrm{p}<0: 01$.

Table 3. Event study and pre- and post-MAD difference tests (robustness checks)

\begin{tabular}{l|ccc|ccc|ccc}
\hline & \multicolumn{3}{|c|}{ Pre-MAD } & \multicolumn{3}{c|}{ Post-MAD } & \multicolumn{3}{c}{ Difference } \\
Variable & Coef & SE & Sign & Coef & SE & Sign & Coef & SE & Sign \\
\hline AR $_{0}$ & 0.1304 & 0.0134 & $* * *$ & 0.1254 & 0.0178 & $* * *$ & -0.0050 & 0.0223 \\
$\mathrm{AV}_{0}$ & 0.0390 & 0.0093 & $* * *$ & 0.0325 & 0.0086 & $* * *$ & -0.0066 & 0.0126 \\
$\mathrm{CAR}(-25,-1)^{\mathrm{a}}$ & 0.0667 & 0.0204 & $* * *$ & 0.0923 & 0.0263 & $* * *$ & 0.0256 & 0.0333 \\
$\mathrm{CAR}(-5,-1)^{\mathrm{a}}$ & 0.0434 & 0.0093 & $* * *$ & 0.0542 & 0.0116 & $* * *$ & 0.0108 & 0.0149 \\
$\mathrm{CAR}(-25,-1)^{\mathrm{b}}$ & 0.0721 & 0.0165 & $* * *$ & 0.0948 & 0.0220 & $* * *$ & 0.0228 & 0.0275 \\
$\mathrm{CAR}(-5,-1)^{\mathrm{b}}$ & 0.0505 & 0.0090 & $* * *$ & 0.0640 & 0.0125 & $* * *$ & 0.0136 & 0.0154 \\
\hline
\end{tabular}

$* \mathrm{p}<0: 10, * * \mathrm{p}<0: 05, * * * \mathrm{p}<0: 01$.

a No rumors

${ }^{\mathrm{b}}$ Post-MAD if year is greater or equal to 2006

Table 4. Profit analysis and pre- and post-MAD difference tests

\begin{tabular}{l|ccc|ccc|ccc}
\hline & \multicolumn{3}{|c|}{ Pre-MAD } & \multicolumn{3}{c|}{ Post-MAD } & \multicolumn{3}{c}{ Difference } \\
Variable & Coef & SE & Sign & Coef & SE & Sign & Coef & SE & Sign \\
\hline Average profit & 0.0066 & 0.0031 & $* *$ & 0.0079 & 0.0041 & $*$ & 0.0014 & 0.0051 \\
Average profit $^{\mathrm{a}}$ & 0.0029 & 0.0025 & & 0.0082 & 0.0035 & $* *$ & 0.0052 & 0.0043 \\
\hline
\end{tabular}

$* \mathrm{p}<0: 10, * * \mathrm{p}<0: 05, * * * \mathrm{p}<0: 01$

${ }^{a}$ No rumors 
Table 5. Descriptive statistics and Pre- and post-MAD difference tests

\begin{tabular}{|c|c|c|c|c|c|c|c|c|c|c|}
\hline \multirow[b]{2}{*}{ Variable } & \multicolumn{4}{|c|}{ Pre-MAD (64.79\%) } & \multicolumn{4}{|c|}{ Post-MAD (35.21\%) } & \multirow[b]{2}{*}{ Diff } & \multirow[b]{2}{*}{ Sign } \\
\hline & Mean & SD & Min & Max & Mean & SD & Min & Max & & \\
\hline Ownership concentration & 0.5745 & 0.2056 & 0.1469 & 0.9335 & 0.5730 & 0.2081 & 0.1811 & 0.8950 & -0.0015 & \\
\hline Family firm & 0.4565 & & & & 0.4800 & & & & 0.0235 & \\
\hline Industrial firm & 0.5652 & & & & 0.6400 & & & & 0.0748 & \\
\hline Financial firm & 0.1304 & & & & 0.2000 & & & & 0.0696 & \\
\hline Ordinary share & 0.7174 & & & & 0.9200 & & & & 0.2026 & $* *$ \\
\hline Firm size & 5.1851 & 0.8186 & 3.7214 & 7.6000 & 5.4008 & 0.7859 & 4.1188 & 7.0380 & 0.2157 & \\
\hline Liquidity & 0.0021 & 0.0026 & 0.0001 & 0.0126 & 0.0029 & 0.0030 & 0.0001 & 0.0112 & 0.0009 & \\
\hline
\end{tabular}

$* \mathrm{p}<0: 10, * * \mathrm{p}<0: 05, * * * \mathrm{p}<0: 01$. Two-sample t-tests for continuous variables and two-sample tests of proportions for dummy variables

Table 6. Regression analysis

\begin{tabular}{|c|c|c|c|c|c|c|}
\hline \multirow[b]{2}{*}{ Variable } & \multicolumn{3}{|c|}{$\begin{array}{c}\text { Model }[1] \\
\operatorname{CAR}(-5,-1) / \operatorname{CAR}(-5,0)\end{array}$} & \multicolumn{3}{|c|}{$\begin{array}{c}\text { Model [2] } \\
\text { CAR(-5,-1)/CAR(-5,0) }\end{array}$} \\
\hline & Coef & SE & Sign & Coef & $\mathrm{SE}$ & Sign \\
\hline Post-MAD & 0.2219 & 0.1880 & & -0.0463 & 0.2453 & \\
\hline Ownership concentration & -2.0005 & 1.1634 & $*$ & -1.8042 & 0.9882 & $*$ \\
\hline Family firm & -0.5332 & 0.3860 & & -0.5416 & 0.3747 & \\
\hline Industrial firm & -0.6008 & 0.6209 & & & & \\
\hline Financial firm & -0.3208 & 0.4182 & & & & \\
\hline Common stock & -0.4380 & 0.4403 & & & & \\
\hline Firm size & -0.2382 & 0.3193 & & & & \\
\hline Liquidity & -61.3149 & 50.8368 & & & & \\
\hline Rumors & -0.1368 & 0.3338 & & & & \\
\hline Constant & 3.9135 & 3.1296 & & 1.7222 & 0.9217 & $*$ \\
\hline $\mathrm{R}^{2}$ & 0.1828 & & & 0.0945 & & \\
\hline
\end{tabular}

$* \mathrm{p}<0: 10, * * \mathrm{p}<0: 05, * * * \mathrm{p}<0: 01$. Inference is based on robust SEs.

Table 7. Nearest-neighbor and propensity-score matching

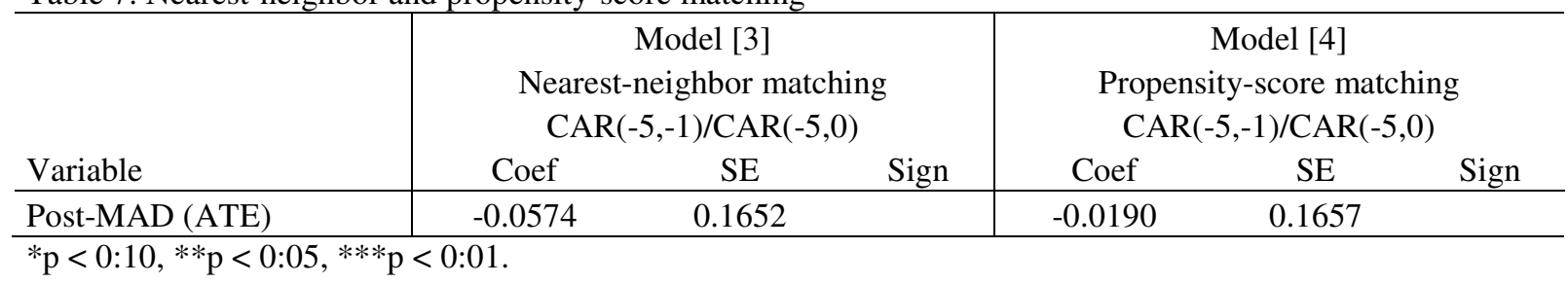


Table 8. Poolability test

\begin{tabular}{|c|c|c|c|c|c|c|c|c|c|}
\hline \multirow[b]{2}{*}{ Variable } & \multicolumn{3}{|c|}{$\begin{array}{l}\text { Model [5] } \\
\text { CAR-ratio }\end{array}$} & \multicolumn{3}{|c|}{$\begin{array}{l}\text { Model [6] } \\
\text { CAR-ratio }\end{array}$} & \multicolumn{3}{|c|}{$\begin{array}{l}\text { Model [7] } \\
\text { CAR-ratio }\end{array}$} \\
\hline & Coef & SE & Sign & Coef & SE & Sign & Coef & SE & Sign \\
\hline Ownership concentration (Post-MAD) & 1.9942 & 1.6819 & & 2.0147 & 1.2624 & & 2.3493 & 1.3939 & $*$ \\
\hline Family firm (Post-MAD) & 0.2195 & 0.6109 & & & & & & & \\
\hline Industrial firm (Post-MAD) & 1.4002 & 1.0477 & & & & & 0.6401 & 0.4140 & \\
\hline Financial firm (Post-MAD) & 0.1418 & 0.6969 & & & & & & & \\
\hline Ordinary share (Post-MAD) & -0.3407 & 0.5922 & & & & & & & \\
\hline Firm size (Post-MAD) & 1.1021 & 0.6501 & $*$ & 0.5930 & 0.3813 & & 0.3909 & 0.1879 & $* *$ \\
\hline Liquidity (Post-MAD) & -24.9541 & 77.8692 & & & & & & & \\
\hline Rumors (Post-MAD) & 0.1211 & 0.6076 & & & & & & & \\
\hline Post-MAD & -7.4934 & 4.9496 & & -4.3409 & 2.7215 & & -3.5253 & 1.6494 & $* *$ \\
\hline Ownership concentration & -2.3901 & 1.3828 & $*$ & -2.1267 & 1.1425 & $*$ & -2.4766 & 1.3707 & $*$ \\
\hline Family firm & -0.6444 & 0.4987 & & & & & -0.6061 & 0.4356 & \\
\hline Industrial firm & -1.0806 & 1.0223 & & & & & & & \\
\hline Financial firm & -0.3615 & 0.6629 & & & & & & & \\
\hline Ordinary share & -0.1792 & 0.4514 & & & & & -0.4216 & 0.3022 & \\
\hline Firm size & -0.6861 & 0.5942 & & -0.3510 & 0.3584 & & & & \\
\hline Liquidity & -18.3377 & 49.8653 & & & & & & & \\
\hline Rumors & -0.1889 & 0.5412 & & & & & & & \\
\hline Constant & 6.5210 & 4.7327 & & 3.4802 & 2.6121 & & 2.1379 & 1.1776 & $*$ \\
\hline Poolability F-test & 1.0300 & & & & & & & & \\
\hline $\mathrm{R}^{2}$ & 0.2686 & & & 0.1156 & & & 0.1279 & & \\
\hline
\end{tabular}

${ }^{*} \mathrm{p}<0: 10, * * \mathrm{p}<0: 05, * * * \mathrm{p}<0: 01$. Inference is based on robust SEs. 


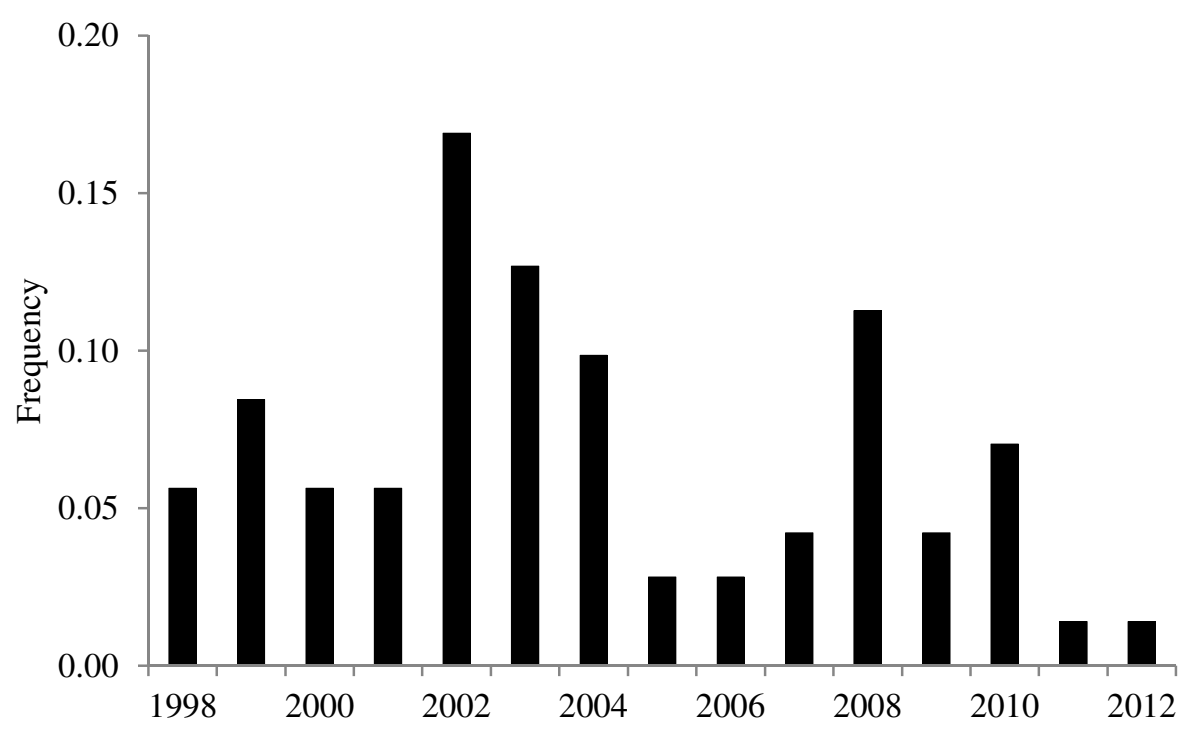

Figure 1. Frequency of tender offers per year

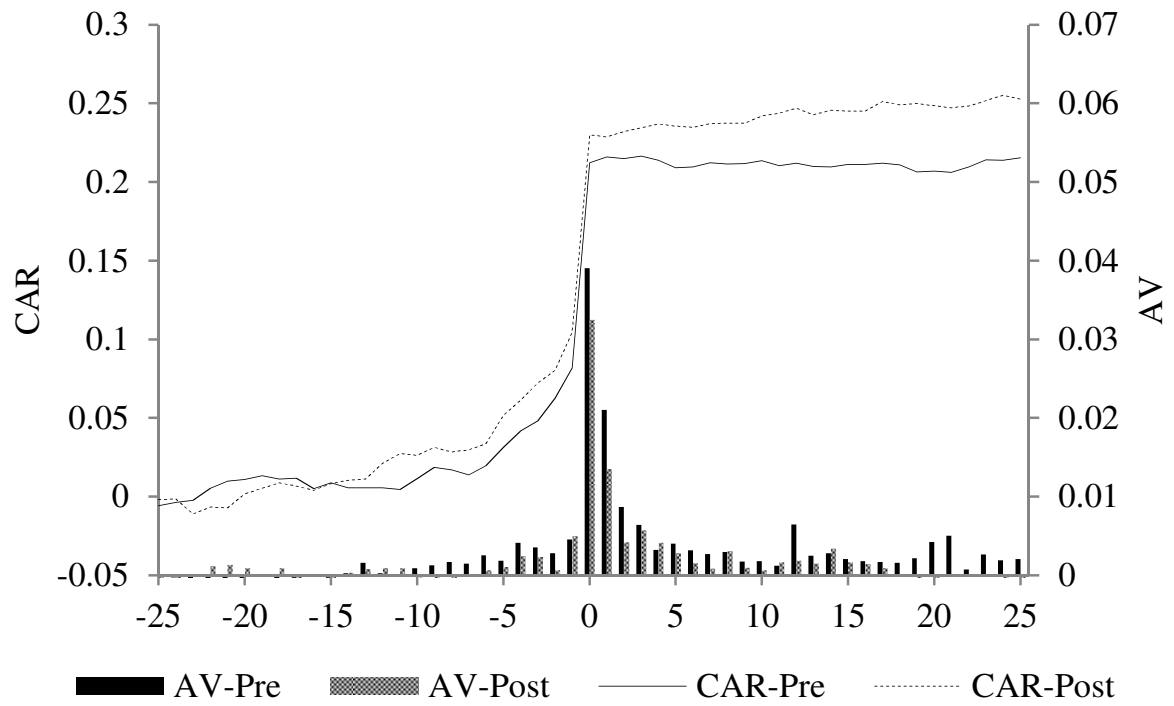

Figure 2. CAR e AV in the pre- and post-MAD period 

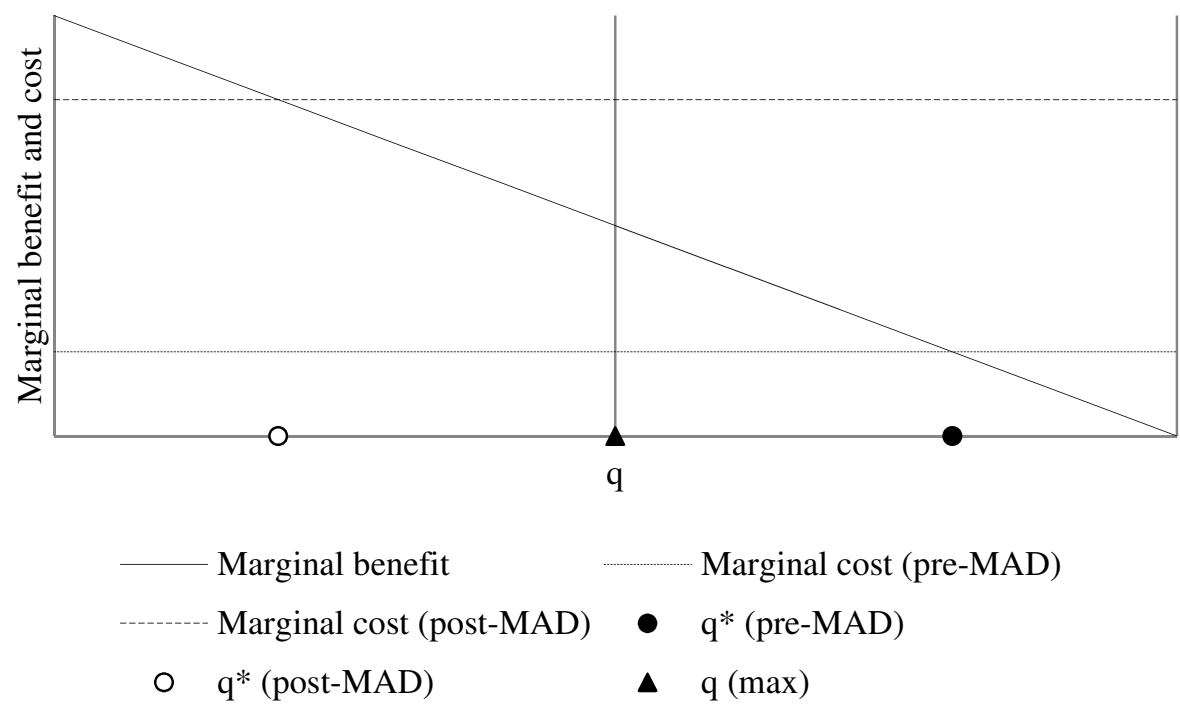

Figure 3. Marginal benefits and costs of insider trading in the pre- and post-MAD period

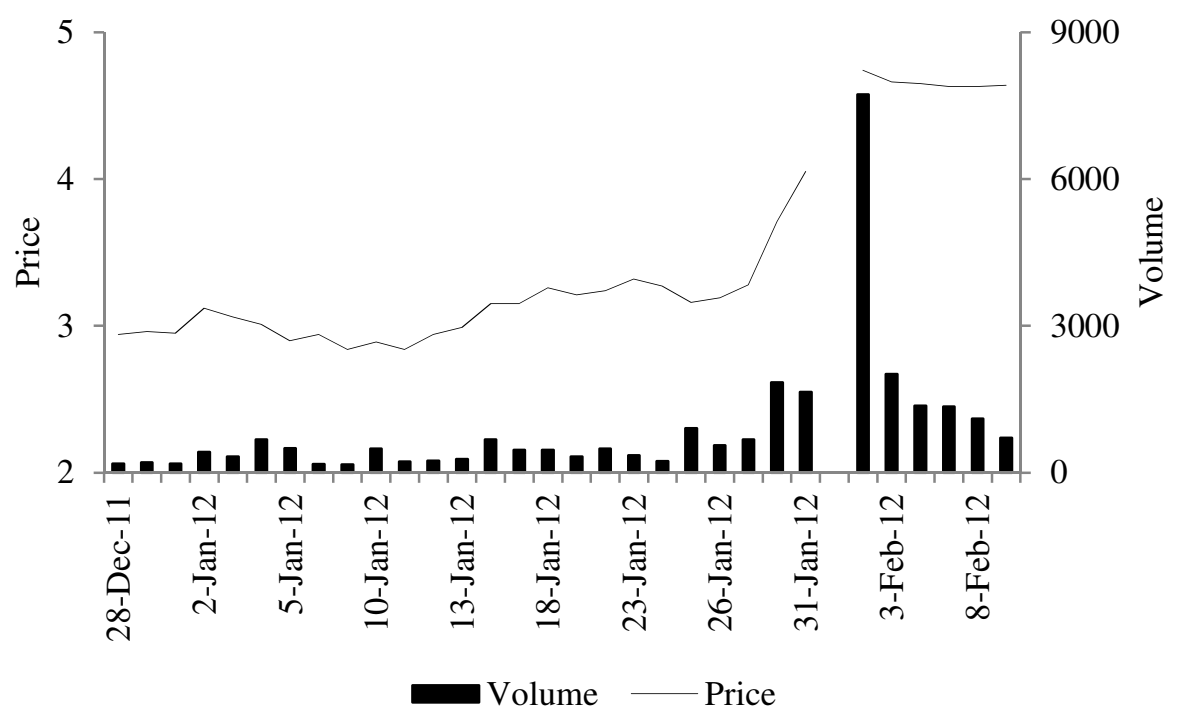

Figure A1. Benetton prices and volumes 
1 As Madura et al. (2014: 515) note '(t)he theoretical foundation for insider-trading arguments is the assumption that insiders will only reveal their private information if they can profitably trade on it. If there is no legal way to profit from insider information, and the enforcement of anti-insider-trading laws is efficient, there would be no motivation for insiders to hold onto their private information in order to eventually profit from it.'

${ }^{2}$ A recent strand of literature even questions the inspiring principles and legitimacy of insider-trading laws (e.g., Padilla 2011). While we deem mentioning this strand of literature important, discussing it in depth would take us too far afield with respect to the main topic of our research.

${ }^{3}$ An example is the voluntary tender offer of convertible savings shares of Marzotto in September 2007, which was excluded from the analysis because it was preceded by the July 2007 tender offer (the latter, however, is included in the sample).

${ }^{4}$ In the case of the Italian market, Baccolini et al. (1991) use the event-study methodology on a sample of 18 firms in the period before the approval of the national anti-insider-trading law (Law 157/1991), and find evidence of abnormal returns in the days preceding the publication of privileged information concerning acquisitions, earnings surprises or changes in ownership.

${ }^{5}$ We believe there are theoretical reasons for preferring the industry-adjusted model in the particular context of our study. In the market-adjusted model, the expected return is estimated as a market index return. This model could obscure certain structural characteristics of the security, which, however, a sector index (being composed of comparable firms) takes into account. In the market model, the expected return is estimated using a regression model. 
Since the degree of liquidity of some of the securities in our sample is relatively limited, the application of this model could result in an underestimation of the beta of the security with a consequent overestimate of the abnormal returns.

${ }^{6}$ To test the statistical significance of the results, we consider both parametric tests (Boehmer et al. 1991) and non-parametric tests (Wilcoxon test), as well as bootstrap tests. As the results obtained using the three methods are qualitatively similar, we only report the traditional parametric tests.

7 Several measures for volumes and abnormal volumes exist. Different measures often produce comparable results (Cervellati et al. 2014). For methods similar to those followed in our study see, inter alia, Pacini and Marlett (2001) and Clarkson et al. (2006).

${ }^{8}$ In Italy, there are no mandatory restrictions on insider dealing (e.g., blackout periods), but only disclosure requirements.

${ }^{9}$ This formulation is based on the more general model by Becker (1968) on the economics of crime and is presented in these terms in Balducci et al. (2001). A similar model is applied to the topic of tax evasion in Allingham and Sandmo (1972).

${ }^{10} \mathrm{We}$ do not have detailed information on the budget dedicated by Consob to enforcing the MAD. However, publicly available data reveal that Consob's total budget remained quite stable in the years before and after the reform. Given the broadening of the definition of privileged information, this evidence is very likely to have resulted in fewer funds and resources available per investigation. In support of this interpretation, we report that, following the introduction of the MAD, the number of insider-trading investigations started by Consob has been greatly reduced (from 94 in the 1998-2004 period to 21 in the 2005-11 
period). This evidence, probably due to limited per-operation resources, may actually suggest that $\pi$ decreased after the reform.

${ }^{11}$ Note that $\partial \pi / \partial \theta<0$ is a necessary but not sufficient condition for the result.

12 We repeated the analysis considering the period $[-25,-1]$, and obtained qualitatively similar results. However, we only report the results for the period $[-5,-1]$, since Figure 2 and Tables 2 and 3 show that the largest part of the market reaction occurs in the last five days prior to the announcement of the tender offer.

${ }^{13}$ It is furthermore plausible that in larger firms the number of subjects involved in the organization of the tender offer is greater (e.g. because they participate in technical committees), and, therefore, the larger probability of rumors and indiscretions may result in an abnormal market reaction. Lastly, it is in case of larger firms that the weight of trading from foreign countries is greater, making monitoring more difficult.

${ }^{14}$ It is reasonable to hypothesize that potential insiders have found alternative ways to use their private information, for example, by using derivatives on the security undergoing the tender offer to best take advantage of leverage effects. 


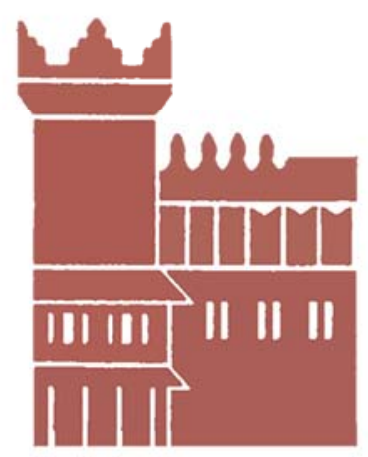

Alma Mater Studiorum - Università di Bologna DEPARTMENT OF ECONOMICS

Strada Maggiore 45

40125 Bologna - Italy

Tel. +39051 2092604

Fax +390512092664

http://www.dse.unibo.it 